Supporting Information

\title{
Highly cationized and porous hypercrosslinked polymer (HCP) nanospheres for composite anion exchange membranes
}

Tong Huang, ${ }^{\mathrm{a}, \mathrm{b}}$, Junfeng Zhang ${ }^{\mathrm{b}}$, Xin Liu ${ }^{\mathrm{b}}$, Jiandang Xue ${ }^{\mathrm{b}}$, Haifei Jiang ${ }^{\mathrm{a}, \mathrm{b}}$, Yanxiong

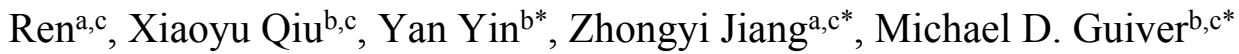

${ }^{a}$ Key Laboratory for Green Chemical Technology, Ministry of Education of China, School of Chemical Engineering and Technology, Tianjin University, Tianjin 300072, China

${ }^{b}$ State Key Laboratory of Engines, Tianjin University, Tianjin, 300072, China

${ }^{c}$ Collaborative Innovation Center of Chemical Science and Engineering (Tianjin), Tianjin 300072, China

* To whom correspondence should be addressed

E-mail:

michael.guiver@outlook.com

zhyjiang@tju.edu.cn

yanyin@tju.edu.cn 
Table S1. Elemental analyses of TP-HCP and QTP-HCP

\begin{tabular}{ccccc}
\hline Sample & $\begin{array}{c}\mathrm{C} \\
{[\text { atom\%] }}\end{array}$ & $\begin{array}{c}\mathrm{N} \\
{[\text { atom\%] }}\end{array}$ & $\begin{array}{c}\mathrm{H} \\
\text { [atom\%] }\end{array}$ & $\begin{array}{c}\mathrm{C} / \mathrm{N} \text { ratio } \\
-\end{array}$ \\
\hline TP-HCP $^{\mathrm{a}}$ & 73.57 & 0.30 & 6.05 & 245.23 \\
QTP-HCP $^{\mathrm{a}}$ & 54.98 & 3.65 & 7.53 & 15.06 \\
QTP-HCP $^{\mathrm{b}}$ & 83.3 & 5.51 & - & 15.12 \\
\hline
\end{tabular}

abtained by elemental analysis (EA)

bObtained by XPS

Table S2. Comparison of ion density and porosity of common porous organic materials reported in ion conducting applications

\begin{tabular}{ccccc}
\hline Sample & $\begin{array}{c}\text { Material } \\
\text { category }\end{array}$ & $\begin{array}{c}\text { BET value } \\
{\left[\mathrm{m}^{2} \mathrm{~g}^{-1}\right]}\end{array}$ & $\begin{array}{c}\text { Ion density } \\
{\left[\mathrm{mmol} \mathrm{g}^{-1}\right]}\end{array}$ & Reference \\
\hline QTP-HCP-NS & HCP & 706 & 3.65 & This work \\
S-POP-B & HCP & 682 & 2.90 & {$[1]$} \\
PAPOP-DD-0.5 & HCP & 589 & 2.20 & {$[2]$} \\
SPAF-0.5 & PAF & 670 & 3.84 & {$[3]$} \\
UiO-66(SO 3$)_{2}$ & MOF & 35 & 4.87 & {$[4]$} \\
PSM-2 & MOF & 294 & 1.56 & {$[5]$} \\
MIL-101-SO $3 \mathrm{H}$ & MOF & 1599 & 2.78 & {$[6]$} \\
TpTa-SO 3 H & COF & 215 & 3.47 & {$[7]$} \\
COF-IL & COF & 291 & 3.12 & {$[8]$} \\
COF-QA-2 & COF & 56 & 2.34 & {$[9]$} \\
QPIM-1 & PIM & 337 & 2.12 & {$[10]$} \\
\hline
\end{tabular}




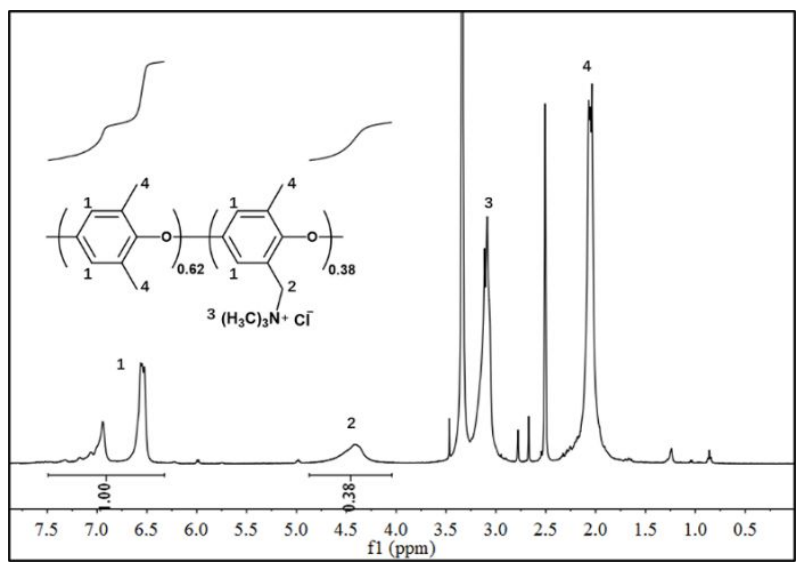

Figure S1. ${ }^{1} \mathrm{H}$ NMR spectrum of QPPO polymer.

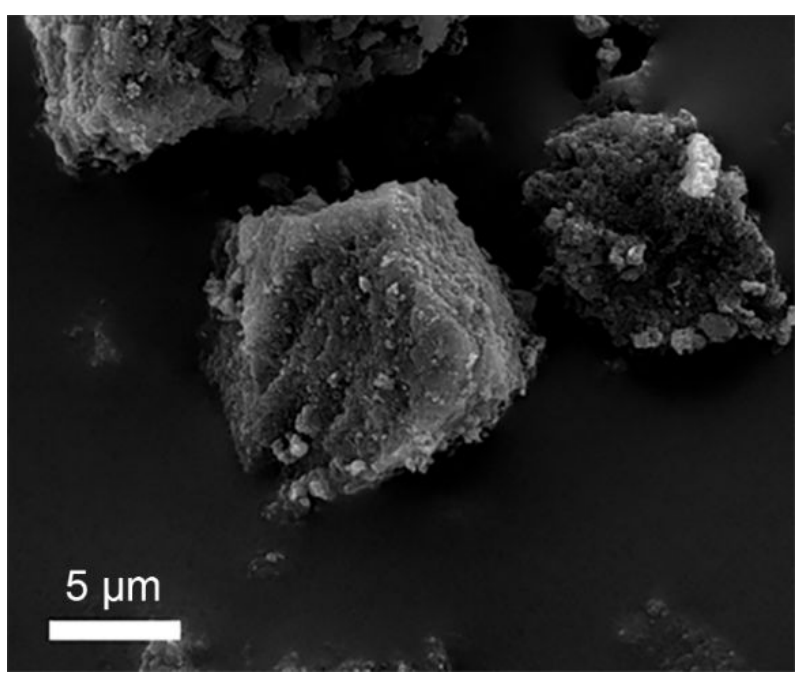

Figure S2. SEM image of bulk particle morphology of QTP-HCP directly after cationization.
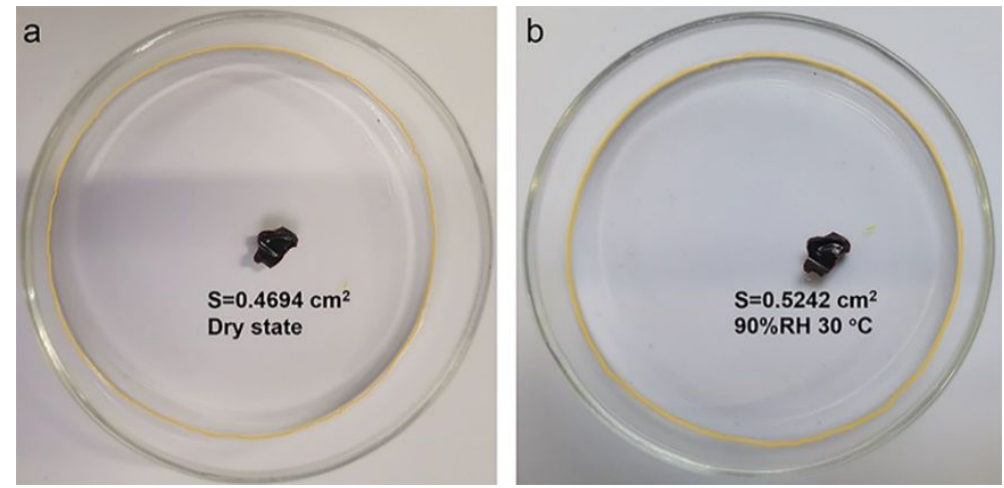

Figure S3. (a) Appearance and area of the QTP-HCP-NS monolith in dry state. (b) Appearance and area of the monolith of QTP-HCP nanospheres after equilibration at $90 \% \mathrm{RH}$ and $30^{\circ} \mathrm{C}$ for $12 \mathrm{~h}$. 


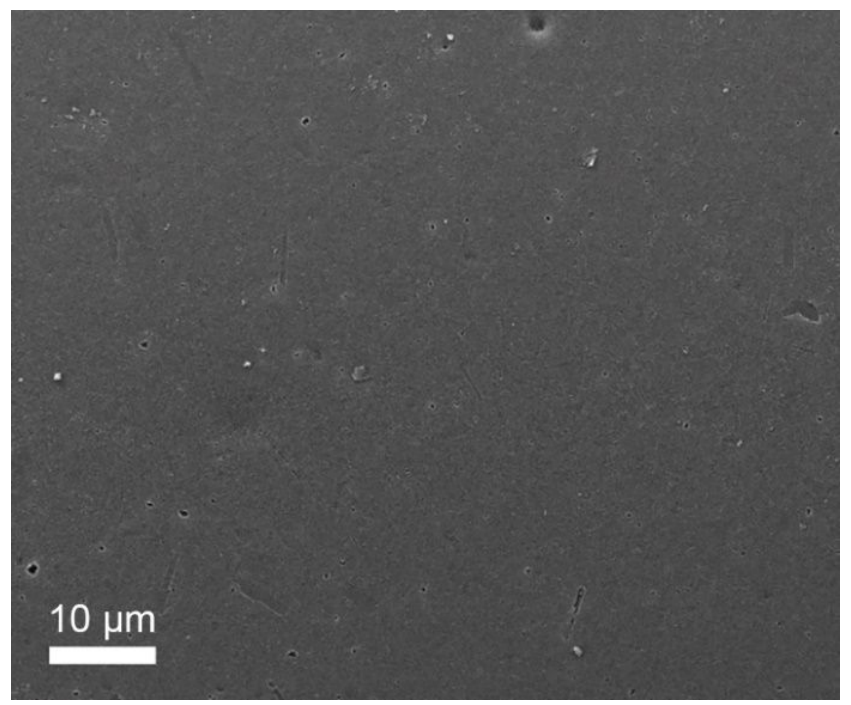

Figure S4. SEM image showing the relatively smooth upper surface of QTP-HCP-NS monolith.

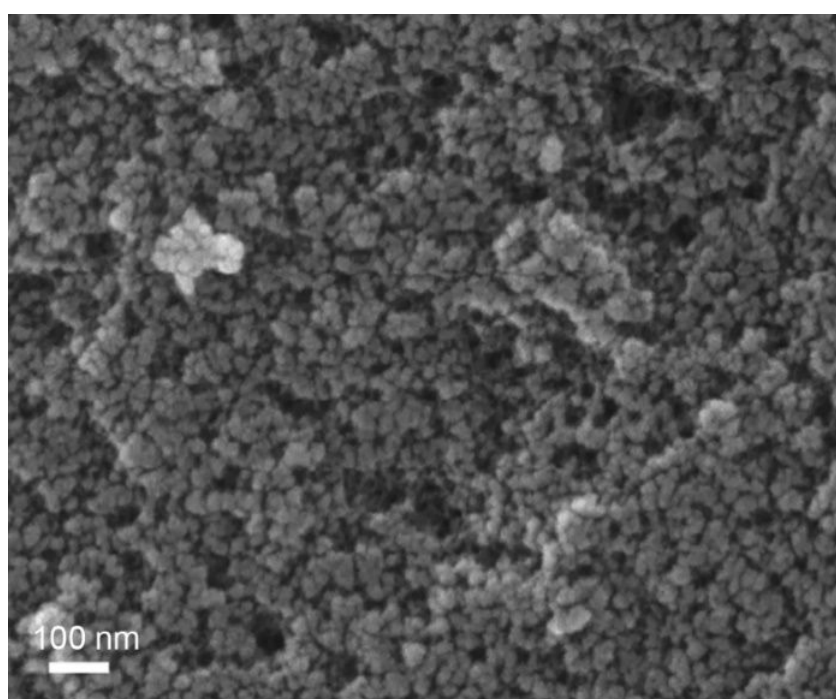

Figure S5. SEM image of the relatively loosely packed QTP-HCP-NS at the bottom surface of the monolith. The ball milling is at a rotation rate of $350 \mathrm{rpm}$. 


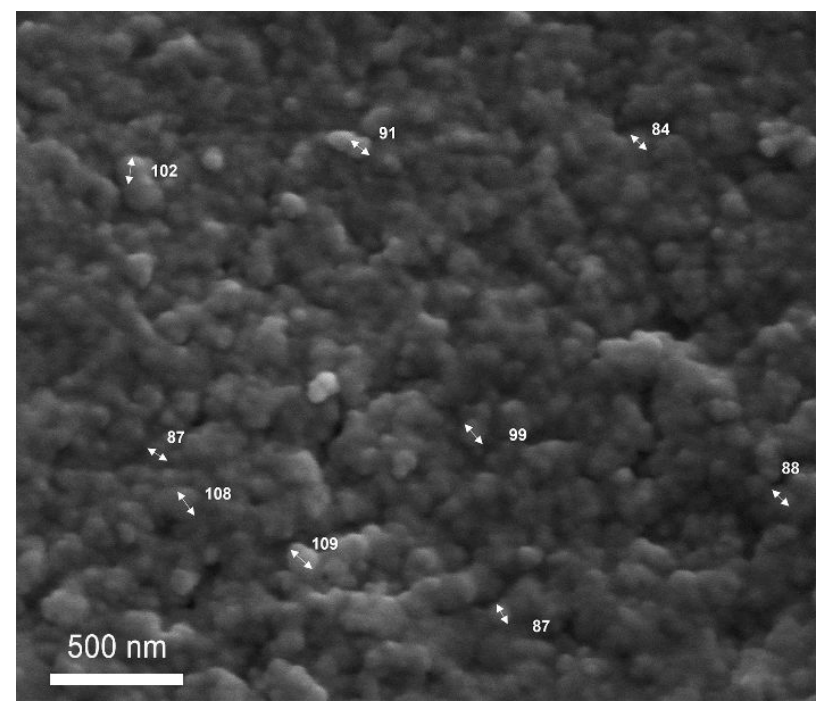

Figure S6. SEM image of QTP-HCP-NS obtained by ball milling at a rotation rate of $300 \mathrm{rpm}$. The diameters of nanospheres increase to $\sim 100 \mathrm{~nm}$ at the slower rotation rate.

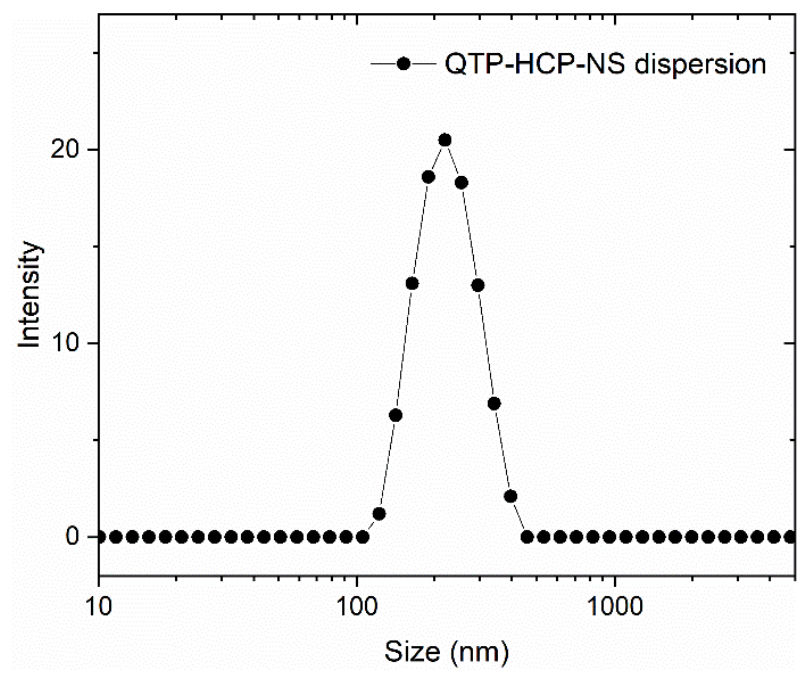

Figure S7. Dynamic light scattering (DLS) curve of QTP-HCP-NS NMP dispersion. 


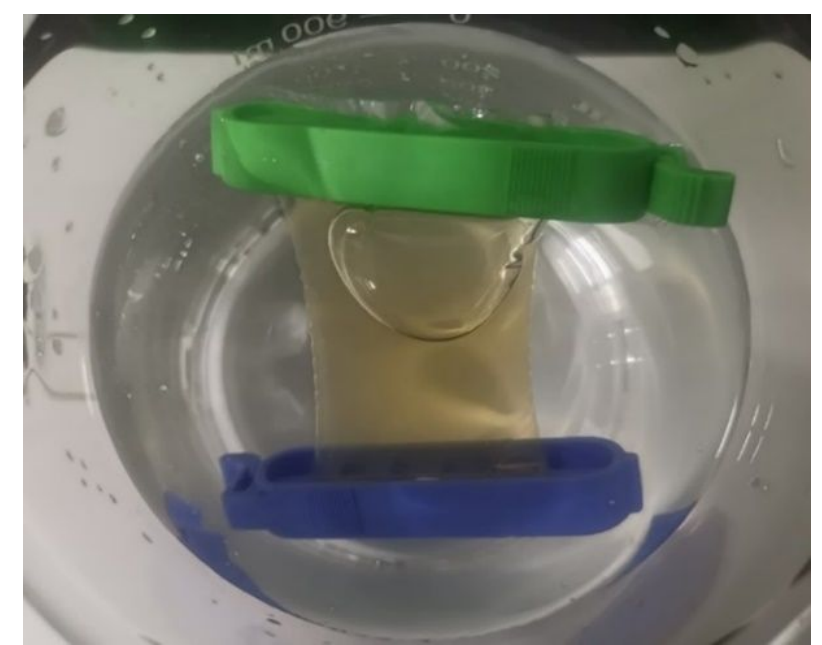

Figure S8. Photographic image of a colloidal dispersion of QTP-HCP-NS equilibrated in DI water through a dialysis membrane $(500 \mathrm{Da})$ for $24 \mathrm{~h}$.

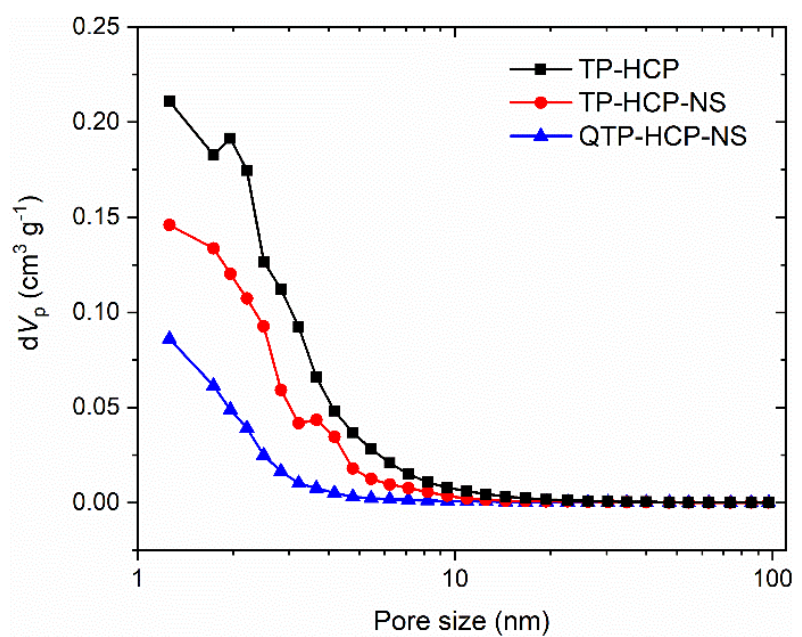

Figure S9. Pore size distribution of TP-HCP, TP-HCP-NS and QTP-HCP-NS by BJH analysis. 


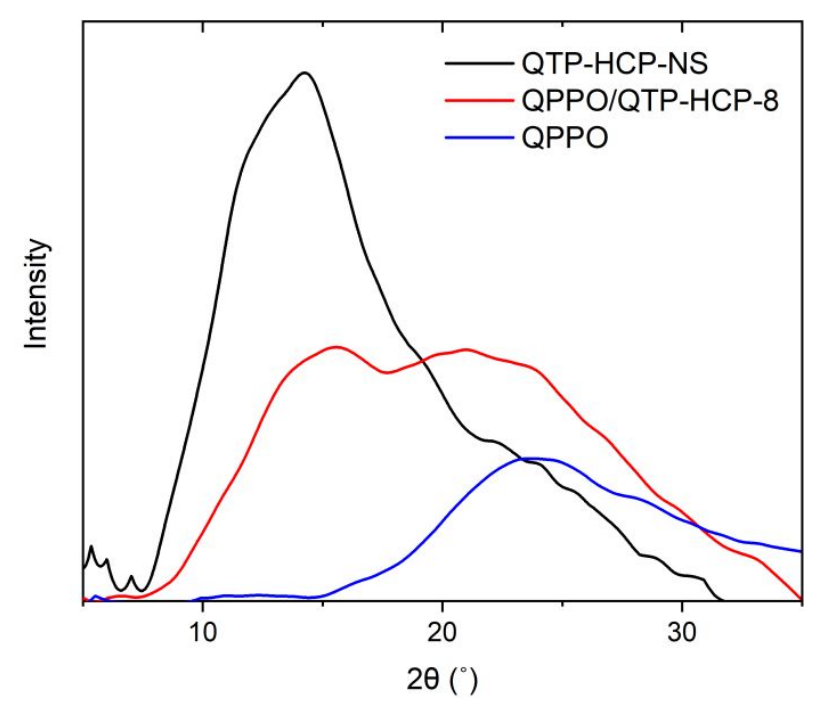

Figure S10. Comparative XRD patterns of QTP-HCP-NS, QPPO/ QTP-HCP-6 composite AEM and QPPO pure AEM.

Broad peaks suggest an amorphous nature for both QTP-HCP-NS filler and QPPO polymer matrix. The $2 \theta$ value of characteristic peaks for QTP-HCP-NS filler is much lower than QPPO matrix, indicating a larger average $d$-spacing ascribed to the intermolecular micropores of the TP-HCP skeleton. The composite QPPO/QTP-HCP8 AEM exhibits both characteristic peaks of QTP-HCP-NS fillers and QPPO matrix. The second peak corresponding to $d$-spacing of QPPO polymers shifts to a lower $2 \theta$ value compared with QPPO AEM, suggesting that the incorporation of QTP-HCP-NS increases the average $d$-spacing of QPPO polymer chains, revealing good interfacial compatibility between filler and polymer matrix.

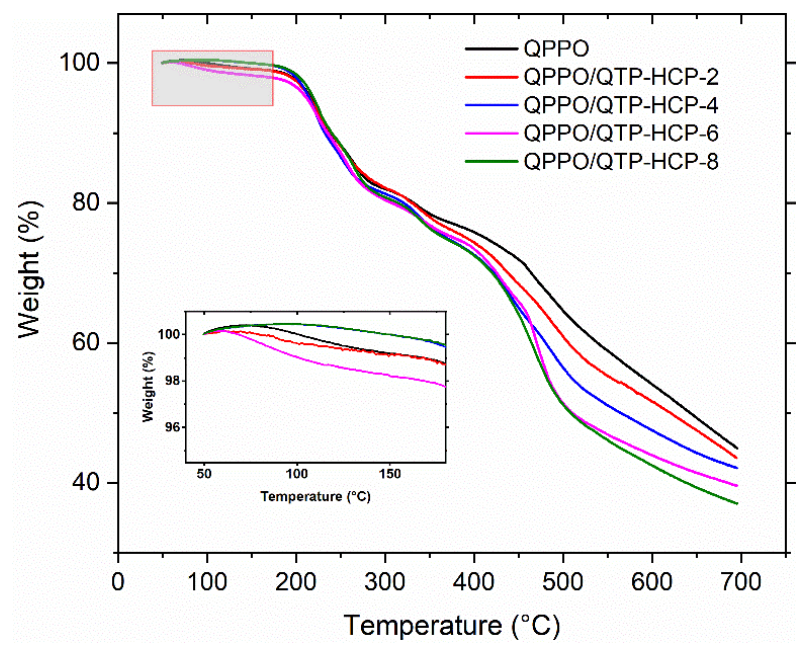

Figure S11. Comparative TGA curves of QPPO and composite AEMs under $\mathrm{N}_{2}$ atmosphere. The inset shows the expanded region before $\sim 5 \% \mathrm{wt}$ loss, indicating evaporation of moisture in the AEMs. 


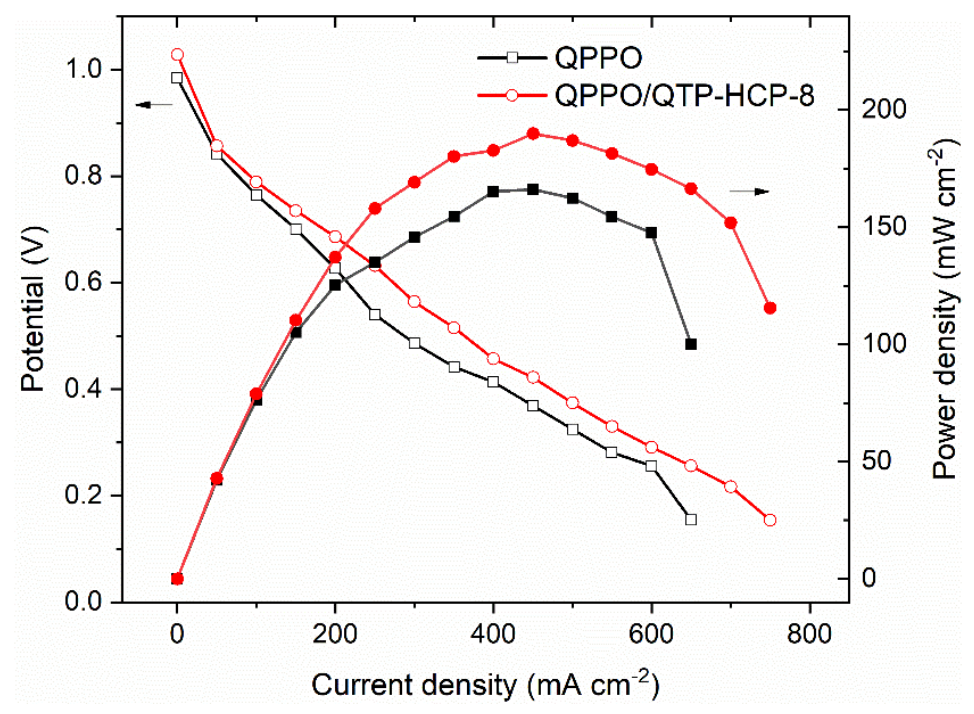

Figure S12. Current-power density curves (filled) and polarization curves (empty) for $\mathrm{H}_{2} / \mathrm{O}_{2}$ AEMFCs assembled with QPPO/QTP-HCP-8 and QPPO AEMs, respectively. All cells were operated with $\mathrm{H}_{2} / \mathrm{O}_{2}$ gases at $60{ }^{\circ} \mathrm{C}, 100 \% \mathrm{RH}$, with $15 \mathrm{kPa}$ backpressure. The anode and cathode catalyst loadings were $0.4 \mathrm{mgPtRu} / \mathrm{cm}^{2}$ and $0.4 \mathrm{mgPt} / \mathrm{cm}^{2}$, respectively. Alkymer I-250 anionic ionomer (EVE Institute, Wuhan, China) in isopropanol/water (2:1) was used to prepare the catalyst ink. 


\section{Reference}

(1) Li, Z.; Yao, Y.; Wang, D.; Hasan, Md. M.; Suwansoontorn, A.; Li, H.; Du, G.; Liu, Z.; Nagao, Y. Simple and Universal Synthesis of Sulfonated Porous Organic Polymers with High Proton Conductivity. Mater. Chem. Front. 2020, 4 (8), 23392345.

(2) Zhu, T.; Shi, B.; Wu, H.; You, X.; Wang, X.; Fan, C.; Peng, Q.; Jiang, Z. Highly Proton Conductive Phosphoric Acid Porous Organic Polymers via Knitting Method. Ind. Eng. Chem. Res. 2021, 60 (17), 6337-6343.

(3) Klumpen, C.; Gödrich, S.; Papastavrou, G.; Senker, J. Water Mediated Proton Conduction in a Sulfonated Microporous Organic Polymer. Chem. Commun. 2017, 53 (54), 7592-7595.

(4) Phang, W. J.; Jo, H.; Lee, W. R.; Song, J. H.; Yoo, K.; Kim, B.; Hong, C. S. Superprotonic Conductivity of a UiO-66 Framework Functionalized with Sulfonic Acid Groups by Facile Postsynthetic Oxidation. Angew. Chem. Int. Ed. 2015, 54 (17), 5142-5146.

(5) Mukhopadhyay, S.; Debgupta, J.; Singh, C.; Sarkar, R.; Basu, O.; Das, S. K. Designing UiO-66-Based Superprotonic Conductor with the Highest MetalOrganic Framework Based Proton Conductivity. ACS Appl. Mater. Interfaces 2019, 11 (14), 13423-13432.

(6) Li, X.-M.; Dong, L.-Z.; Li, S.-L.; Xu, G.; Liu, J.; Zhang, F.-M.; Lu, L.-S.; Lan, Y.Q. Synergistic Conductivity Effect in a Proton Sources-Coupled Metal-Organic Framework. ACS Energy Lett. 2017, 2 (10), 2313-2318.

(7) Chandra, S.; Kundu, T.; Dey, K.; Addicoat, M.; Heine, T.; Banerjee, R. Interplaying Intrinsic and Extrinsic Proton Conductivities in Covalent Organic Frameworks. Chem. Mater. 2016, 28 (5), 1489-1494.

(8) Ding, L.-G.; Yao, B.-J.; Li, F.; Shi, S.-C.; Huang, N.; Yin, H.-B.; Guan, Q.; Dong, Y.-B. Ionic Liquid-Decorated COF and Its Covalent Composite Aerogel for Selective $\mathrm{CO}_{2}$ Adsorption and Catalytic Conversion. J. Mater. Chem. A 2019, 7 (9), 4689-4698.

(9) He, X.; Yang, Y.; Wu, H.; He, G.; Xu, Z.; Kong, Y.; Cao, L.; Shi, B.; Zhang, Z.; Tongsh, C.; Jiao, K.; Zhu, K.; Jiang, Z. De Novo Design of Covalent Organic Framework Membranes toward Ultrafast Anion Transport. Adv. Mater. 2020, 2001284.

(10)Huang, T.; Zhang, J.; Pei, Y.; Liu, X.; Xue, J.; Jiang, H.; Qiu, X.; Yin, Y.; Wu, H.; Jiang, Z.; Guiver, M. D. Mechanically Robust Microporous Anion Exchange Membranes with Efficient Anion Conduction for Fuel Cells. Chem. Eng. J. 2021, 418, 129311. 